\title{
Proinflammatory Cytokines IL-2, IL-6 and TNF Alpha as Immunoseralogic Indicators of Chronic Viral Hepatitis B and C in Children
}

\author{
Raba Tatiana \\ Department of Pediatrics, "Nicolae Testemitanu" State University of Medicine and Pharmacy, Republic of Moldova
}

Copyright $(2018$ by authors, all rights reserved. Authors agree that this article remains permanently open access under the terms of the Creative Commons Attribution License 4.0 International License

\begin{abstract}
The role of proinflammatory cytokines IL-2, IL-6, and TNF-a in the pathogenesis of chronic hepatitis B and $\mathrm{C}$ infection was studied in 49 children ages 3 to 18 years. There has been concluded that high IL-2 and low IL-6 serum levels related to hepatic inflammatory activity did not depend on viremia levels. Slow progression of the disease was associated with an insignificant increase of IL-6 and normal TNF-a serum levels. The study results show the importance of proinflammatory cytokines as diagnostic and prognostic indicators in the pathogenesis of chronic hepatitis $\mathrm{B}$ and $\mathrm{C}$ in children.
\end{abstract}

Keywords Cytokines, Children, Chronic Hepatitis B and $\mathrm{C}$ Infection

\section{Introduction}

Pathogenetic mechanisms and factors that lead to chronic hepatitis $\mathrm{B}$ and $\mathrm{C}$ viral infections in children, including the perinatal ones, as well as the role of proinflammatory cytokines have not been sufficiently studied yet. The success of elimination and resolution of hepatitis $\mathrm{B}$ and $\mathrm{C}$ viral infection depends on the age and the immune status of the patient. Most chronic HBV and HCV perinatal infections commonly occur by both vertical (from mother to child) and horizontal transmission, as well as in immunocompromised patients. The immune determinants of a successful HBV clearance haven't been entirely understood, whereas both cellular and humoral immune responses are important. Nevertheless, liver inflammation and disease are also believed to be largely immune-mediated. Cytokines are important mediators between specific and nonspecific, humoral and cellular immunity, providing a protective response of the body against the inflammatory process $[1,4,8]$. Pathogenetic mechanisms and factors contributing to the chronic B and
$\mathrm{C}$ viral infection course in children have been the subject of multiple scientific studies for a long time [2, 3]. In addition, factors like infection pathway, age, antigenic properties of the pathogen and its adaptive capacity $[2,3]$ have played a major role in the occurrence of chronic hepatitis $\mathrm{B}(\mathrm{CHBV})$ and $\mathrm{C}(\mathrm{CHCV})$ viruses. Active replication of $\mathrm{HBV}$ starts only 4-5 weeks after the penetration of the causative agent into liver cells [3, 7]. Evolution of chronic hepatitis $\mathrm{B}$ in children is characterized by the predominance of the immunoactive phase [1].

An important characteristic of $\mathrm{HBV}$ is the ability to integrate into the human genome, causing a change in the sequence of nucleotides and a violation of antigen expression with the formation of HBsAg-negative forms of $\mathrm{HBV}[3,5]$. A significant role in the pathogenesis of HBV infection is the ability of the causative agent to cause mutations in the S-region or pre-S-region, thereby modifying its antigenicity and suppressing the synthesis of anti-HBs, creating conditions for itself to escape from the immune control of the organism [2, 3].

Compared to chronic HBV infection, the main role in the pathogenesis of chronic $\mathrm{HCV}$ (CHCV) infection belongs to the direct cytopathic effect of $\mathrm{HCV}$ and direct replication of the virus to billions of copies per day immediately after its penetration into the hepatocyte $[2,3]$. There is an opinion that, in chronic HCV infection, the major role in the elimination of the virus from the body is played by cellular immune responsiveness between antigen-specific T-helper $1(\mathrm{CD} 4+)$ and cytotoxic T-lymphocytes $(\mathrm{CD} 8+)$ [2, 3]. The body protective immune response has an indirect role in the damage of infected hepatocytes of $\mathrm{HCV}$ and is provided by the action of cytotoxic T-lymphocytes and cross autoimmune reactions [2, 4]. The variability of $\mathrm{HCV}$ and its low immunogenicity are of major importance for a long-term persistent replication $[2,3]$. By changing continuously its antigenic structure, HCV escapes from the body's immune 
control, reproducing itself intensively [2, 3]. This variability of $\mathrm{HBV}$ determines the development of subclinical, erased and difficult to diagnose "occult" forms of chronic HBV rarely seen in children.

Proinflammatory cytokines-interleukin-2 (IL-2), interleukin-6 (IL-6), and tumor necrosis factor- $\alpha$ (TNF- $\alpha$ ) play an important role in both detection of $\mathrm{HBV}$ or $\mathrm{HCV}$ and suppression of its replication, which contributes to the regulation of the equilibrium of subpopulations of T-lymphocytes, their further activation, differentiation of effector cells and the synthesis of anti-inflammatory cytokines [4,7]. Proinflammatory cytokines IL-2, IL-6, TNF- $\alpha$ are activated from the onset of HBV or HCV replication and the increase of viremia titer $[2,3]$. According to their functional activity, cytokines are divided into pro-inflammatory (IL-1 $\beta$, IL-2, IL-6, TNF- $\alpha$, INF- $\gamma$ ) and anti-inflammatory (IL-4, IL-10) [7, 8]. T-helper cells via cytokines recognize the pathogen and stimulate activation of T-killer lymphocytes to fight off the infected cells, whereas the T-suppressor lymphocytes help suppresses this process. [9].

The main synthesis of IL-2 is carried out by T-helper lymphocytes, cytotoxic T-cells up to $20 \%$, and can be stimulated by other biologically active substances like IL-1, IL-6, TNF [8]. The proinflammatory cytokine IL-2 is the main triggering pathogenetic factor of a specific and non-specific immune response to pathogenic antigens, which promotes the activation of IL-2 receptors located on T-lymphocytes, influences maturation of B-lymphocytes, stimulates the formation of acute phase proteins in hepatocytes, neutrophils NK and makes connection between the immune, nervous and endocrine systems [7, 8].

IL-6 belongs to a group of inflammatory cytokines synthesized by macrophages, $\mathrm{T}$ and B-lymphocytes, and which provides proliferation of thymus cells, B-lymphocytes, cytotoxic lymphocyte precursors, granulocytes and macrophages, as well as hepatocyte production of acute inflammatory proteins $[7,8]$. TNF- $\alpha$ is produced by macrophages, mast cells and $\mathrm{T}$ - and B-lymphocytes and refers to lymphotoxins that acts as the penetration gate of the pathogen that induces the synthesis of acute inflammation and apoptosis proteins $[2,3,8]$.

IL-4, IL-13, IL-10 cytokines help in regulation and control of the level of proinflammatory cytokines in blood [7, 8]. T-helper 1 (Th1) lymphocytes have been shown to promote activation of cytotoxic T suppressor $(\mathrm{CD} 8+)$ by T-helper 1 (Th1) and enhance the synthesis of interferon- $\gamma$ (INF- $\gamma$ ), IL-2, TNF- $\alpha$ ) $[2,3,4]$. Activation of T-helper 2 (Th2) lymphocytes stimulates the humoral immune link, promoting the maturation of B lymphocytes and the synthesis of anti-inflammatory cytokines [3, 8]. Activation of the immune response system by Th1-type promotes the removal of the virus from the body, whilst Th2-type promotes the persistence of infection $[2,8]$. Recent studies have shown the presence of T helper (Th1 and Th2) CD4 + lymphocyte deficiency in the blood of patients with $\mathrm{CHCV}$ infection $[2,3]$. This can lead to a breakdown in the synthesis of proinflammatory and anti-inflammatory cytokines, their inactivation and cytokine balance, as well as formation of chronic inflammation $[7,8]$.

Objectives: To study the serum level of proinflammatory cytokines IL-2, IL-6, and TNF-a in children with chronic HBV and HCV infections, depending on both the activity level of chronic viral inflammatory process in liver and viremia level.

\section{Materials and Methods}

\subsection{Study Group and Methodology}

The study was conducted on 181 children with chronic viral hepatitis B (in 107 cases) and C (in 84 cases), ages 3 to18 years [Table 1]. In order to determine the particularities of the cellular immunity in 50 children with CHBV (in 25 cases) and $\mathrm{CHCV}$ (in 25 cases), we proposed to study the cellular immune status of CD3 T lymphocytes and their subpopulations before the study and after undergoing the antiviral treatment [Table 2]. Cellular immunity has been studied in 49 patients by using monoclonal reactants, whereas the levels of pro-inflammatory cytokine IL-2, IL-6 and TNF- $\alpha$ have been studied in 49 children with chronic HBV (in 30 patients) and HCV (in 19 patients) [Table 3]. The control group included 21 "somatically healthy" children aged between 4-18 years.

The diagnosis of chronic HBV and HCV was defined in accordance with international and national recommendations $[9,10]$. The methods used in survey data collection are the anamnesis, examination of the patient, investigation of virological markers as $\mathrm{HVB}$, HVC, ADN HVB, ARN HVC and their genotype, ARN VHD (PCR by Real Time).

According to clinical indications, magnetic resonance abdominal tomography (MRT) was performed. No investigation on HBV genotype was conducted. The degree of liver fibrosis was examined in children over 5 years with a weight of more than $20 \mathrm{~kg}$ via elastography (FibroScan 502, device Ecosens, France). A liver biopsy was carried out by the author, via Menghini needle puncture under general anesthesia, and followed by histological examination of the biopsy specimen.

The detection of IL-2, IL- 6 , TNF- $\alpha$ was performed in the clinical immunology laboratory via the immunoenzyme test system (manufactured by «Vector-Best», Russia). The participation of the patient in the research was confirmed by the written consent of the parents. The scientific project was approved on September 14, 2015 by the Ethics Research Committee of the "Nicolae Testemitanu" State University of Medicine and Pharmacy from the Republic of Moldova. 
Table 1. Baseline characteristics of patients with $\mathrm{CHBV}$ and $\mathrm{CHCV}$ infection.

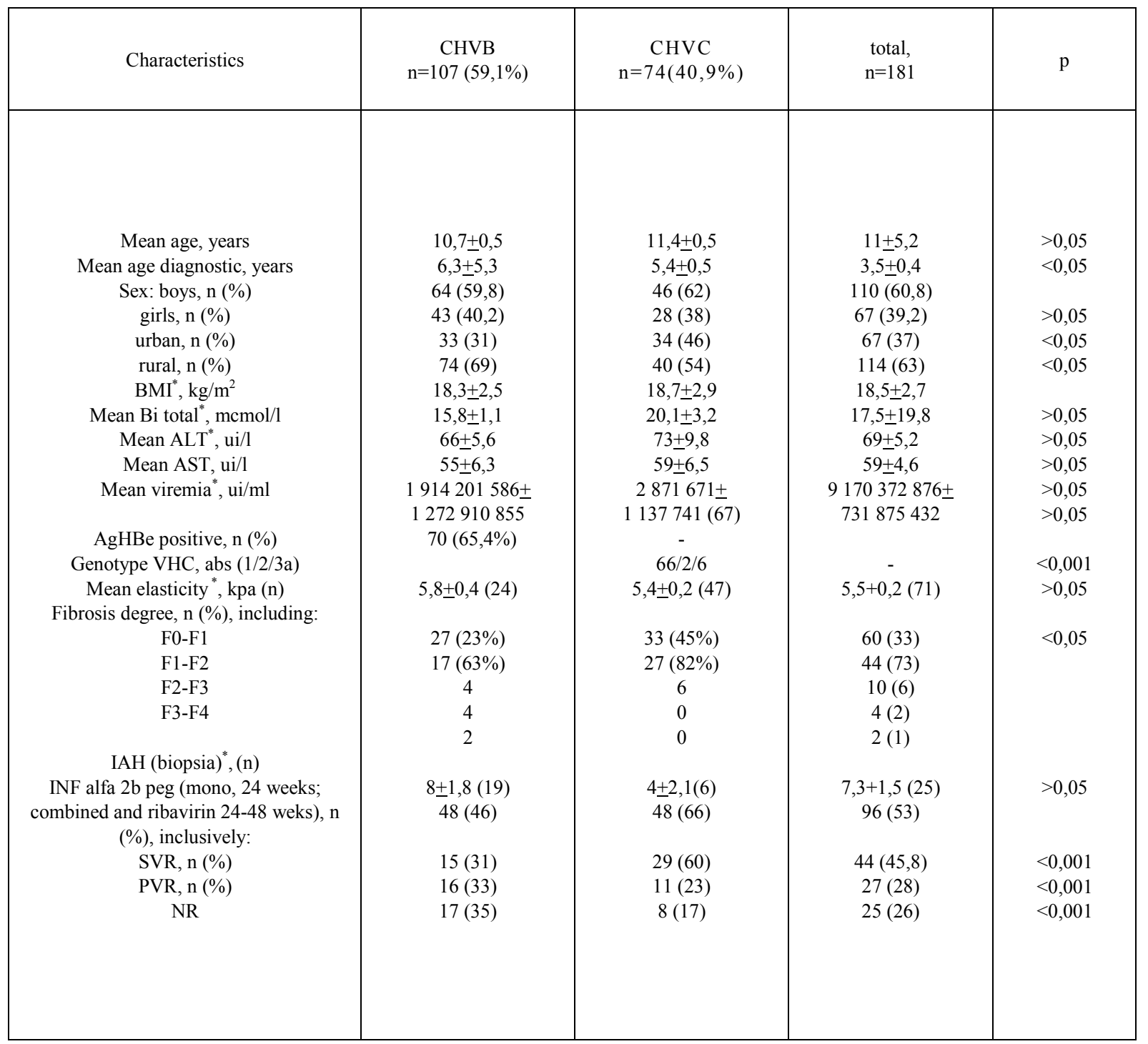

Note: ${ }^{*} \pm$ indicate standard deviation, BMI - body mass index Ketle, ALT - alaninaminotransferase, AST-aspartataminotransferaze, Bi - total bilirubin, HAI- histological activity index, SVR- sustained virologic responser, PVR- partial virologic response, NR - non responder.

The statistical analysis was carried out via StatSoft Statistica version 6.0 ru., which identified t-Student criterion, the exact Fisher test and the chi-square test. Cases with $\mathrm{p} \leq 0.05$ were determined to be statistically significant. 
Table 2. Characteristics of cellular immunity in $\mathrm{CHBV}$ and $\mathrm{CHCV}$-infected children, \% (abs)

\begin{tabular}{|c|c|c|c|c|c|c|c|}
\hline \multirow{3}{*}{ Characteristics } & \multirow{2}{*}{\multicolumn{2}{|c|}{$\begin{array}{c}\text { Control group }(\mathrm{n}=22) \\
1\end{array}$}} & \multirow{2}{*}{\multicolumn{2}{|c|}{$\begin{array}{c}\begin{array}{c}\mathrm{CHBV} \\
(\mathrm{nr}=107)\end{array} \\
2 \\
\end{array}$}} & \multirow{2}{*}{\multicolumn{2}{|c|}{$\begin{array}{c}\begin{array}{c}\mathrm{CHCV} \\
(\mathrm{nr}=74)\end{array} \\
3 \\
\end{array}$}} & \multirow{3}{*}{$\mathrm{p}_{1,2}$} \\
\hline & & & & & & & \\
\hline & $\mathrm{nr}$ & $\mathrm{M} \pm \mathrm{m}$ & $\mathrm{nr}$ & $\mathrm{M} \pm \mathrm{m}$ & $\mathrm{nr}$ & $\mathrm{M} \pm \mathrm{m}$ & \\
\hline $\begin{array}{c}\mathrm{CD} 3, \mathrm{~T} \text { total } \\
\text { lymphocyte, \% } \\
\text { CD3, abs } \\
\end{array}$ & 22 & $\begin{array}{l}66 \pm 1,4 \\
1,8 \pm 0,2 \\
\end{array}$ & 25 & $\begin{array}{l}52 \pm 2,8 \\
1,6+0,3\end{array}$ & 25 & $\begin{array}{l}60+1,3 \\
1,6+0,2\end{array}$ & $\begin{array}{l}<0,001,<0,01,<0,01 \\
>0,05,>0,05,>0,05\end{array}$ \\
\hline $\begin{array}{c}\text { CD19, B total } \\
\text { lymphocyte, } \% \\
\text { CD19, abs } \\
\end{array}$ & 22 & $\begin{array}{c}18 \pm 1,0 \\
0,58 \pm 0,1\end{array}$ & 25 & $\begin{array}{l}13,4+1,7 \\
0,33+0,1\end{array}$ & 25 & $\begin{array}{l}12,3+1,2 \\
0,36+0,1\end{array}$ & $\begin{array}{c}<0,05<0,001 \quad>0,05 \\
<0,05<0,05>0,05\end{array}$ \\
\hline $\begin{array}{l}\text { CD4, T helper } \\
\text { lymphocyte,\% } \\
\text { CD4 abs }\end{array}$ & 22 & $\begin{array}{l}39 \pm 1,8 \\
1,1 \pm 0,2 \\
\end{array}$ & 25 & $\begin{array}{c}36+1,8 \\
1+0,2\end{array}$ & 25 & $\begin{array}{l}36+1,3 \\
0,9+0,1\end{array}$ & $\begin{array}{l}>0,05>0,05>0,05 \\
>0,05>0,05>0,05\end{array}$ \\
\hline $\begin{array}{l}\text { CD8,T suprresor } \\
\text { lymphocyte } \% \\
\text { CD8, abs } \\
\end{array}$ & 22 & $\begin{array}{l}27 \pm 1,1 \\
0,8 \pm 0,1\end{array}$ & 25 & $\begin{array}{l}18+2,3 \\
0,48+0,1\end{array}$ & 25 & $\begin{array}{l}23+1,0 \\
0,67+0,1\end{array}$ & $\begin{array}{l}<0,01<0,05<0,05 \\
<0,05>0,05>0,05\end{array}$ \\
\hline CD4/CD8 & 22 & $1,43 \pm 0,1$ & 25 & $3,06+0,6$ & 25 & $2,05+0,4$ & $<0,05>0,05>0,05$ \\
\hline$(\mathrm{CD} 4+\mathrm{CD} 8) / \mathrm{CD} 3$ & 22 & $0,97 \pm 0,02$ & 22 & $1,05+0,04$ & 22 & $0,97+0,02$ & $>0,05>0,05>0,05$ \\
\hline $\begin{array}{l}\text { CD5,T mature } \\
\text { lymphocite, } \% \\
\text { CD5 abs }\end{array}$ & 22 & $\begin{array}{c}61 \pm 0,97 \\
1,7 \pm 0,1\end{array}$ & 22 & $\begin{array}{l}47+3,4 \\
1,2+0,1\end{array}$ & 22 & $\begin{array}{l}52+1,9 \\
1,7+0,2\end{array}$ & $\begin{array}{l}<0,001<0,001>0,05 \\
<0,05>0,05>0,05\end{array}$ \\
\hline $\begin{array}{c}\text { CD16, natural killer } \\
\text { (NK), \% } \\
\text { CD16 (NK, abs) } \\
\end{array}$ & 22 & $\begin{array}{c}12 \pm 1,2 \\
0,33 \pm 0,04 \\
\end{array}$ & 15 & $\begin{array}{r}14,7+1,1 \\
0,32+0,03 \\
\end{array}$ & 15 & $\begin{array}{c}18+0,9 \\
0,44+0,1 \\
\end{array}$ & $\begin{array}{l}>0,05<0,001<0,05 \\
>0,05>0,05>0,05\end{array}$ \\
\hline $\begin{array}{c}\text { CD HLA DR, } \\
\text { T lymphocyte activation/ } \\
\text { B lymphocyte, } \% \\
\text { CD HLA DR, abs }\end{array}$ & 22 & $\begin{array}{c}29,9 \pm 1,98 \\
0,9 \pm 0,1\end{array}$ & 17 & $\begin{array}{r}21,6+2,5 \\
0,5+0,1\end{array}$ & 17 & $20+1,6$ & $<0,05<0,001>0,05$ \\
\hline
\end{tabular}

Investigations of the cellular immune status in children with $\mathrm{CHBV}$ and $\mathrm{CHCV}$ revealed the presence of total T-cell lymphocyte imbalance, expressed by a decrease of CD3, CD19, CD4+, CD8+, CD5, CD HLA DR and a disturbance of the immune balance; an increase in the CD4 +/CD8 + immunoregulatory index; an increase in the percentage of CD16 natural killer cells; the presence of the „double positive" phenotype $(\mathrm{CD} 4+, \mathrm{CD} 8+)>\mathrm{CD} 3$ in $36 \%$ of children with CHBV and in $41 \%$ of CHCV patients [Table 2]. These confirmed the involvement of autoimmune self-defense mechanisms under „chronic infectious stress" at viral antigen stimulation against the background of T -lymphocyte immune deficiency.

\section{Results and Discussions}

The average age of children with $\mathrm{CHBV}$ and $\mathrm{CHCV}$ was 11 years, predominantly boys. In $18 \%$ of children with HBV, the disease was associated with delta infection. Among children with chronic HBV, a pronounced fibrosis of the liver F3 was detected in $3(21 \%), \mathrm{F} 2$ in $2(15 \%)$, and F0-F1 in 9 cases (64\%) respectively. Genotype 1c prevailed in $96 \%$ of patients with CHCV and only one child presented genotype $3 \mathrm{a}$. CHCV was characterized by minimal fibrosis $\mathrm{F} 0-\mathrm{F} 1$ - in 9 patients $(64 \%), \mathrm{F} 2$ in 5 patients $(36 \%)$ and lack of $\mathrm{F} 3$.

$\mathrm{CHBV}$ and $\mathrm{CHCV}$ were characterized by an active inflammatory process in $57 \%$ of patients. The ALT enzyme was more than 1.5 times greater in 13 children, 3 times higher in 14 children and only in 5 cases the values exceeded by $4-10$ times the permissible standards. $50 \%$ of $\mathrm{HBV}$-infected children were characterized by immune-active phase with HBV DNA ranging between $2000-<109 / \mathrm{ml}$ and minimal fibrosis". 
Table 3. Serum level of cytokines in CHBV and CNCV-infected children

\begin{tabular}{|c|c|c|c|c|c|c|c|}
\hline \multirow{3}{*}{ Cytokines } & \multicolumn{2}{|c|}{ Control group $(\mathrm{n}=21)$} & \multicolumn{2}{|c|}{$\begin{array}{l}\text { CHBV } \\
(\mathrm{nr}=30)\end{array}$} & \multicolumn{2}{|c|}{$\begin{array}{l}\mathrm{CHCV} \\
(\mathrm{nr}=19)\end{array}$} & \multirow{3}{*}{$\mathrm{p}_{1,2 ;} \mathrm{p}_{1,3 ;} \mathrm{p}_{2,3}$} \\
\hline & \multicolumn{2}{|c|}{$\mathrm{p}_{1}$} & \multicolumn{2}{|c|}{$\mathrm{p}_{2}$} & \multicolumn{2}{|c|}{$\mathrm{p}_{3}$} & \\
\hline & $\begin{array}{c}\mathrm{nr} \\
\text { patients }\end{array}$ & $\mathrm{M} \pm \mathrm{m}$ & $\begin{array}{c}\mathrm{nr} \\
\text { patients }\end{array}$ & $\mathrm{M} \pm \mathrm{m}$ & $\begin{array}{c}\mathrm{nr} \\
\text { patients }\end{array}$ & $\mathrm{M}+\mathrm{m}$ & \\
\hline $\mathrm{IL}-2, \mathrm{pg} / \mathrm{ml}$ & 21 & $1,5 \pm 0,3$ & 30 & $108 \pm 47$ & 19 & $113 \pm 34$ & $<0,05<0,05>0,05$ \\
\hline IL-6, pg/ml & 21 & $4,5 \pm 0,4$ & 30 & $41 \pm 22$ & 19 & $29 \pm 14$ & $>0,05>0,05>0,05$ \\
\hline TNF- $\alpha, p g / 1$ & 21 & $4 \pm 0,5$ & 30 & $7,6 \pm 0,7$ & 19 & $7 \pm 0,5$ & $>0,05>0,05>0,05$ \\
\hline
\end{tabular}

Note: $\mathrm{M} \pm \mathrm{m}$ - mean and statistical deviation; $\mathrm{p}$ - comparison between groups of patients; statistical tests: $\mathrm{t}$-Student; Fisher criterion.

Immunotolerant phase with a high level of viremia and HBV DNA range of $10^{9}-10^{12}$ ui / $\mathrm{ml}$ among the examined patients was not detected. In 6 children with HBV, a delta infection with a high level of viremia and HDV RNA range of $1,3 \times 10^{8}-1,4 \times 10^{9}$ ui/ $\mathrm{ml}$ was diagnosed. The development of CHVC was characterized by low viral replication in $61 \%$ with a HCV RNA range of $<600000$ ui / $\mathrm{ml}$ and absence or minimal liver fibrosis.

Analysis of the serum level of proinflammatory cytokines revealed a significant increase in the level of IL-2 in blood, compared to the control group $\left(\mathrm{p}_{1-3}<0,05\right.$, $\left.\mathrm{p}_{2-3}<0,05\right)$ in CHBV and CHCV -contaminated children (Table 3).

The level of IL-6 was higher among children with CHBV infection, compared to children with $\mathrm{CHCV}\left(\mathrm{p}_{1-3}\right.$ $<0,05)$. Given that IL-6 promotes the differentiation of T-lymphocytes towards Th2 (CD4 +), which suppresses the immune response, the relatively low concentration of IL-6 in CHVC compared to CHVB has been associated with a minimal activity level of inflammatory process in the liver.

A slight but significant increase in the serum level of IL- 6 and minimal fibrosis in the examined HCV patients is probably due to a weak immunological response and low HCV replication due to insufficient differentiation of T-lymphocytes. The study of the serum level of TNF- $\alpha$ in children with $\mathrm{CHBV}$ and $\mathrm{CHCV}$ did not reveal any significant changes (Table 3 ).
TNF- $\alpha$ is known as a local-action proinflammatory cytokine, which activates those factors responsible for the acute inflammatory process induced via blood, and correlates with the disease severity and a good immune response.

A comparative analysis of the concentration of proinflammatory cytokines IL-2, IL-6 and TNF- $\alpha$ was performed based on the degree of activity of the inflammatory process of $\mathrm{CHBV}$ and $\mathrm{CHCV}$ infection and the level of viremia.

A direct and reliable relationship between the IL-2 indices in the blood and the activity of the inflammatory process was revealed [Figure 1]: the higher the cytolysis, the higher the level of IL-2 in CHBV and CHCV-infected children $\left(\mathrm{p}_{1,2,3}<0,05\right)$. The TNF- $\alpha$ values in blood of the examined patients were within the permissible limits, whereas the concentration of IL-6 in blood of CHBV and CHCV-infected children was slightly increased and did not depend on the degree of activity of the inflammatory process $\left(\mathrm{p}_{1,2,3}>0,05\right)$.

It is necessary to mention that in CHBV-infected children, the serum values of IL- 6 and TNF- $\alpha$ show no diagnostic significance since the disease develops into the immune-active phase with low viraemia over the years. Therefore, there has been detected a presence of imbalance in the synthesis of proinflammatory mediators followed by a secondary immunodeficiency within studied children. 


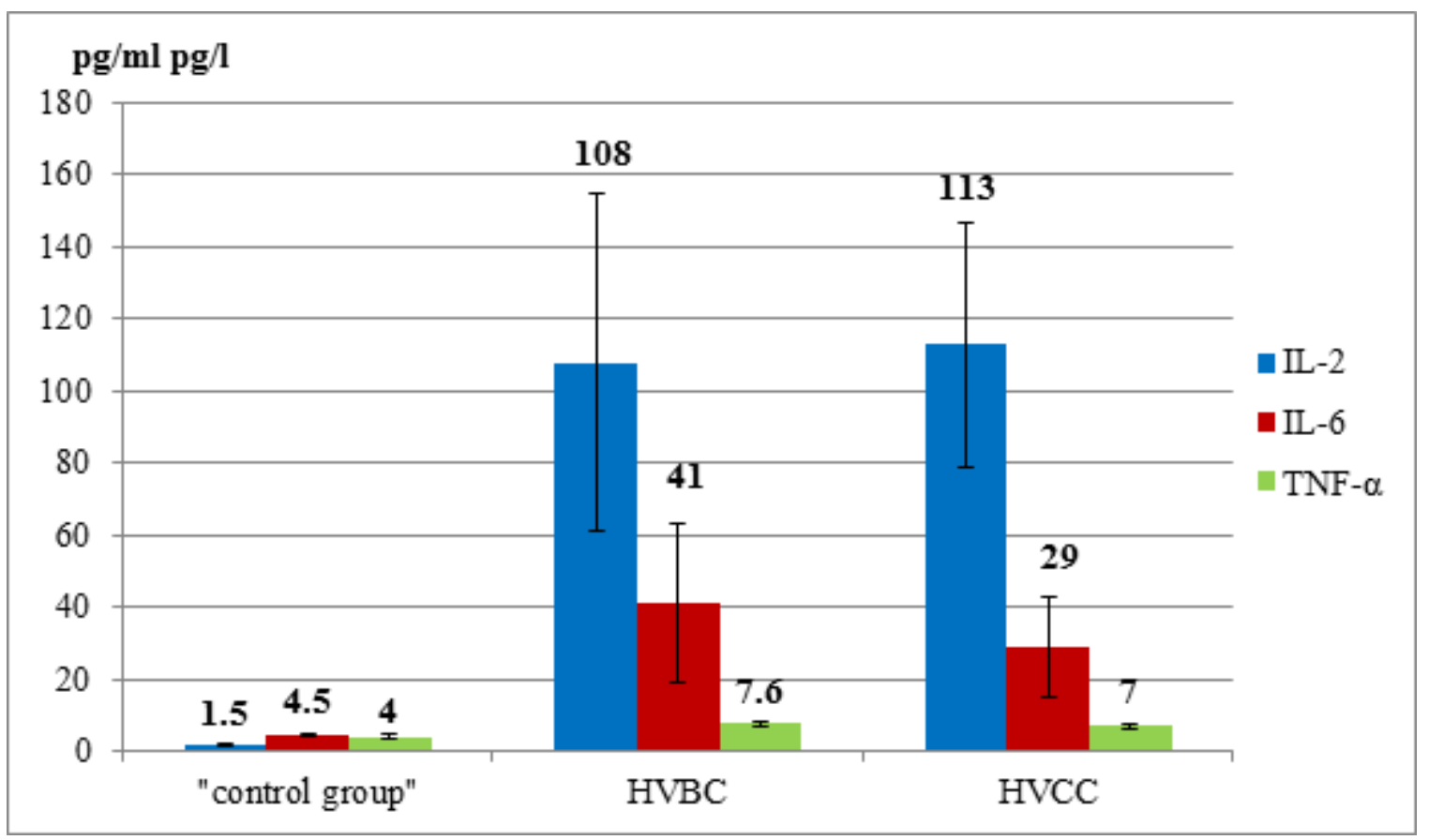

Figure 1. Blood serum level of proinflammatory cytokines IL-2, IL-6 (în pg/ml), TNF- $\alpha$ (pg/l) in CHBV and CHCV - infected children

An analysis on relationship between the blood serum level of IL-2, IL- 6 and TNF- $\alpha$ and the level of HBV and $\mathrm{HCV}$ replication has been carried out. The concentration of IL-2 and IL-6 in blood was significantly increased in CHBV-infected patients with DNA HBV within $>2000$ $10^{8} \mathrm{ui} / \mathrm{ml}$, whereas for those with CHBV infection the DNA less than $2000 \mathrm{ui} / \mathrm{ml}$ - higher values ( $\mathrm{p}>0,05)$.

Among children with $\mathrm{CHCV}$ and ARN HCV $<600000$ ui $/ \mathrm{ml}$, the level of IL-2 and IL-6 in blood was significantly higher than in viremia more than $600000 \mathrm{ui} / \mathrm{ml}(\mathrm{p}>0,05)$.

The serum level of TNF- $\alpha$ in CHBV and CHCV -infected children did not reveal dependence on the level of viremia. Taking into account that $50 \%$ of children with HBV infection manifested an immunoactive phase, and $61 \%$ of HCV cases presented low HCV replication, the lack of a reliable relationship between the serum levels of IL-6 and TNF- $\alpha$ and the level of viremia might be due to the interaction of complex regulatory mechanisms which activate various factors and inhibit cytokine production. The slow maturation of cellular and humoral factors of innate and adaptive immunity in children reaches its perfection by $6-7$ years $[2,8]$. HBV or HCV infection in younger children leads to the formation of partial and insufficient immune responses specific to the introduction of the pathogen, which creates conditions for its prolonged persistence in the body.

\section{Conclusions}

Chronic Hepatitis B and C viral infections in children occupy an important share in the etiological structure of chronic hepatitis in children overall, whereas CHBV is predominantly affecting adolescents, and represents a life-threatening issue for public health care services. The primary source of contamination of children with $\mathrm{HBV}$ and $\mathrm{HCV}$ infections is their HBsAg positive mothers or $\mathrm{CHBV}$ and $\mathrm{CHCV}$ during the viral active phase.

The basis of pathogenetic mechanisms of both inflammatory processes and fibrogenesis in viral hepatitis $\mathrm{B}$ and $\mathrm{C}$ in children are cellular immune reactions that result from complicated interaction between $\mathrm{HBV}$ or $\mathrm{HCV}$ and the infected child's organism.

The pro-inflammatory cytokines IL-2, IL- 6 and TNF- $\alpha$ have an important diagnostic and prognostic significance in the pathogenesis of CHBV and CHCV in children. The high serum level of IL-2 in children with CHBV and $\mathrm{CHCV}$ infections significantly correlates with the level of activity of the chronic inflammatory process in the liver and does not depend on the level of viremia. IL-2 in children with CHBV and CHCV is a prognostic predictor of the persistence of inflammatory activity in the liver on the background of a secondary immunodeficiency.

A slight increase in the serum level of IL-6 and a normal level of TNF- $\alpha$ in CHBV-infected children in the immune phase and $\mathrm{CHCV}$ infection with a low degree of viremia confirm the inadequacy of both synthesis and protective immune responses, as well as the violation of regulatory mechanisms in the system of mediators of chronic viral inflammation.

\section{Acknowledgements}

We are very grateful to experts for their appropriate and constructive suggestions to improve this template. 


\section{Conflict of Interests}

The author declares that there is no conflict of interests regarding the publication of this paper.

\section{REFERENSES}

[1] Zinovich Ya.I., Oskirko A.N., Goreglyad N.S., Klyuchareva A.A. Characteristics of chronic hepatitis B of genotype $\mathrm{D}$ in children. Topical issues of infectious diseases: the 6-th Congress of Infectious Diseases of the Republic of Belarus, Vitebsk, 2014, p. 81-82.

[2] Uchaikin V.F, Cherednichenko T.V., Smirnov A.V. Infectious hepatology. Moscow. GEOTAR - Media, 2012, $640 \mathrm{p}$.

[3] Pantya V. Acute and chronic viral hepatitis (etiology, epidemiology, pathogenesis, clinical picture, diagnosis, treatment and prevention). Kishinev, 2014, Sirius Publishing House, 259 p.

[4] Lupashko Yu. Chronic hepatitis and other forms of chronic diffuse liver diseases. Chisinau, 2014, Ericon Publishers, p. $110-123$

[5] Dumbrava V., Lupashko Yu., Turcanu A., Tofan-Scutaru
L., Holban T., Spanu C. Chronic hepatitis and cirrhosis of the virus by viral $\mathrm{B}$ and $\mathrm{D}$ etiology in adults. National clinical protocol. Ministry of Health of the Republic of Moldova. Chisinau, 2015. Available from: http// www.office@ms.gov.md. (date of the application 08.09.2017)

[6] Panigrahi R., Biswas A., Datta S., et al. Anti-hepatitis B core antigen testing with defection and characterisation of occult hepatitis B virus by an in-house nucleic acid testing among blood donors in Behrampur, Ganjam, Orissa in Southeastern India: implications for transfusion. Virol J, 2010; vol.7, p. 204. Available from:

http//www.ncbi.nlm.nih.gov/pmc/articles. (date of the application 02.09.2017)

[7] Ketlinsky S.A., Simbirtsev A.S. Cytokines. SPb: OOO "Publishing House Foliant", 2008, 552 p.

[8] Kalinina N.M., Sosyukin A.E., Vologzhanin D.A. et al. Journal of Cytokines and Inflammation, 2005, vol. 1, p. 28-35. Available from: http//www.cytokines.ru. (date of the application 02.02.2017).

[9] European Association for Study of Liver. EASL. Recommendation on treatment of hepatitis C. J Hepatology, 2015, vol.63 (1), p.199-236.

[10] ESPGHAN. Clinical Practice Guidellines. Consensus of an expert panel on behalf of the European Society of Pediatric Gastroenterologiy, Hepatology and Nutrition. In: Journal of Hepatology, 2013, vol. 59, p. 463-467. 